\title{
An Exploratory Study Investigating How and Why Managers Use Tablets to Support Managerial Decision- Making
}

\author{
Meng Xiao
}

Decision Support Systems Laboratory

Faculty of Information Technology

Monash University

\section{Rob Meredith}

Decision Support Systems Laboratory

Faculty of Information Technology

Monash University

Rob.Meredith@monash.edu

\author{
Shijia Gao \\ Decision Support Systems Laboratory \\ Faculty of Information Technology \\ Monash University
}

\begin{abstract}
Managers are often mobile and a large proportion of their work is dealing with decisions. Although many managers currently use tablet computers in their work, there is little research on the use of tablets for managerial decision-support. This exploratory study aims to investigate the ways in which managers use tablets to support their decision-making and the reasons why they do so. Using Task-Technology Fit theory, semi-structured interviews were conducted with 20 managers, 17 of whom used tablets for their work-related decision-making. The study reveals managers' tablet usage patterns in terms of location, tablet applications, decision activities and types. This study has also found that a range of tablet characteristics and decision-task characteristics affect managers' use of tablets to support decision-making at work. This exploratory study contributes to both academia and industry by providing evidence on the tablet decision-support area, and affording organisations, tablet vendors and tablet application developers informative findings for further improvement in the provision of tabletbased decision support.
\end{abstract}

Keywords: Managers, Technology Use, Tablets, Decision Support, Mobile Decision Support, Business Intelligence, Mobile Business Intelligence, Task-Technology Fit.

\section{Introduction}

The popularity of tablet computers grew sharply after Apple first introduced the iPad in 2010. While sales of new tablets slowed from 2014 to 2016 (Lee et al., 2017), adoption rates among consumers are high: in January 2014, 42\% of US adults owned a tablet (Zickuhr \& Rainie, 2014). With the widespread consumer adoption of tablet computers, it is common to see employees, including managers, using these devices in the workplace (Willis, 2011).

Despite their initial status as a consumer device, tablets offer a wide range of business functionality. The business category was the fastest growing category of applications within Apple's iOS App Store in 2014 (Sacco, 2015). Managerial users of tablet devices are doing so to read documents and communicate (Mayer, Winter, Stock, \& Scholl-Steinepreis, 2014), and some are pushing their IT departments to offer greater access to management support systems such as business intelligence (BI). BI vendors such as Tableau, Business Objects and Cognos offer versions of their software for tablets, while developers highlight mobile decision-support as a top issue driven by managerial demand at all levels of the organisation including senior executives (O'Donnell, Sipsma, \& Watt, 2012). 
Managers are an important group of business users with a large proportion of their work dealing with decisions (Simon, 1960). However, there is little research investigating the use of tablets by managers to support managerial decision-making.

There are two main research questions being addressed in this paper:

1. In what ways do managers use tablet devices to support their managerial decisionmaking?

2. Where tablet devices are used by managers for managerial decision-support, why do they do so?

In addition, a sub-question related to research question two was also addressed:

2a. Where tablet devices are not used by managers who have access to them for managerial decision-support, why do they not do so?

The reason for including the sub-question above is partly opportunistic, as three participants in the study indicated that they no longer, or never have, used their tablets for decisionsupport. Understanding why a manager does not use a tablet for decision support when they have the opportunity to do so adds context and further insight into the reasons why managers who do use their tablets for decision-support do so.

The project is exploratory in nature and to address the research questions we conducted semistructured interviews with 20 managers from a large government authority, 17 of whom used tablets to support some aspect of their decision-making. We used the task-technology fit (TTF) theory (Goodhue \& Thompson, 1995) to inform the design of the interview protocol and guide the analysis of the data collected.

The paper is structured as follows. In the following section, we review the literature on management support using mobile technology. We also offer a brief outline of the TTF theory as it applies to this study. The research design is then presented, followed by results, discussion and a conclusion.

\section{Background}

\subsection{Mobile Decision-Support}

For the purposes of our study, we adopt Mintzberg's (1973) definition of a manager as someone who ensures their organisation achieves its purpose through "planning, organising, staffing, directing, coordinating, reporting, and budgeting" (p.95). As knowledge workers, managers rely on a variety of information sources to inform these activities, including enterprise IT systems such as BI and other management support systems. Managers also tend to be highly mobile, with studies such as Kim (2008) and Yuan, Archer, Connelly, and Zheng (2010) suggesting some managers spend between $30 \%-60 \%$ of their time away from their primary work location.

It follows that mobile technologies may have a significant role to play in the provision of ITbased managerial decision-support. Findings from Gebauer and Shaw (2004) support this premise, showing that managerial users of mobile technologies used mobile applications more often than other categories of employees. Mobile technologies are those which are easily transported by their users, in particular those which can be carried on a regular basis regardless of location such as mobile phones / smartphones, tablets and small notebooks. Some authors also include laptop computers within this definition, although arguably there is a significant difference between the desktop-like experience of using a full laptop computer, and the more ubiquitous but less functional experience of devices using mobile operating systems such as Android and $i O S$.

Research on the use of mobile technology for management support pre-dates the introduction of tablet computers in 2010 (e.g. Cil, Alpturk, \& Yazgan, 2005). However, there is a lack of research on managerial mobile decision-support, with the majority of mobile decision support 
systems (DSS) studies focusing on individual consumers and specific industry applications such as health (Sneha \& Varshney, 2009) and agriculture (Rose et al., 2016). Gao (2013) suggests that more mobile DSS research should be conducted on managerial users, especially senior managers. Gao's study also shows a peak in academic papers addressing mobile DSS in 2007 followed by a sharp decline leading to a small resurgence in 2012. This suggests that tablet computing might have revived interest in this area. Tona and Carlsson (2014) also note an increase in the popularity of mobile BI coincided with the introduction of the iPad in 2010, and O'Donnell et al. (2012) note that developers' interest in mobile BI is strongly driven by senior executive demand for support for the iPad platform. Mayer et al. (2014) found that tablets are the dominant preferred platform for mobile access to management support systems over smartphones, although they note that it is tablet "functionality" rather than tablet devices themselves that is important. Given the potential benefits of mobile decision-support, the importance placed on the topic by decision-support vendors and developers, the demand from managerial users as well as the dominance of tablets as a mobile decision-support platform, it is important to understand managerial tablet use for decision-support.

To date there has been little empirical research on how tablets are used by managers for decision-support and why they do so. Tona and Carlsson (2014) call for more research into the usage of mobile technologies for decision-making, and similarly Mayer et al. (2014) argue strongly for future research and development efforts to focus on managerial usage situations and work styles. Tona and Carlsson (2017) investigate mobile BI use by employees in mobile workplaces including middle- and top-level managers ( $63 \%$ of their sample), but do not exclusively focus on managerial use of tablet-based BI tools, with tablet-use making up just $24 \%$ of their sample. Verkooij and Spruit (2013) conducted a literature review of mobile BI research, identifying six themes in the literature (value creation, application deployment, information security, workforce mobilisation, content delivery and device management) but also did not focus on tablet use specifically, or decision-making processes. Kautzner, Gao, Yeoh, and Wong (2015) studied managerial use of tablets, but did not specifically investigate their use for decision-support.

Buchana and Naicker (2014), on the other hand, did investigate the use of mobile technologies for organisational decision-making. However, their use of the technology acceptance model (TAM) as a theoretical framework for their study means that their results focussed on antecedents leading to an intention to use, rather than a detailed understanding of usage behaviour. While their results showed a positive correlation between behavioural intention to use mobile decision-support and organisational decision-making, a detailed understanding of the nature of mobile technology use for decision-making tasks was not explored.

Our intent in this paper is to investigate both the 'how' (the ways in which) and the 'why' (the reasons for) of managers use of tablet computers to support their decision-making processes.

\subsection{Task-Technology Fit (TTF) Theory}

Given that our study aims to understand how tablets are used by managers to support decisionmaking, not just why they do so, we have adopted the TTF theory (Goodhue \& Thompson, 1995), rather than the TAM theory used by Buchana and Naicker (2014). TTF offers constructs that allow us to investigate characteristics of the user (i.e. managers who are individuals with characteristics different from other non-managerial users), the technology (i.e. tablets that have distinguished characteristics such as mobility and multi-touch interfaces), and the task (i.e. decision making that is a special kind of managerial task). TTF has been used previously in studies of mobile technology (Gebauer \& Shaw, 2004; Gebauer, Shaw, \& Gribbins, 2010; Lee, Cheng, \& Cheng, 2007), as well as DSS (Jarapathirun \& Zahedi, 2007; Parkes, 2012).

TTF posits that the fit between the technology and the task, and the fit between the individual and the technology, determine performance levels when using a technology. Goodhue (1995) argues that "the better fit between technology functionalities, task requirements, and individual abilities will lead to better performance" (p. 1828). In a similar vein, Dishaw and Strong (1999) argue that IT will be used if, and only if, its functions support the user's task. While this study is not concerned with the two "fits" and managerial decision performance as 
such, TTF does provide us with a theoretical framework to structure our investigation of how and why managers use tablets for decision making by focussing on the following three constructs:

i. $\quad$ Characteristics of tablet devices (technology characteristics): features of tablet devices that may contribute to a manager using it for decision-support, including physical characteristics such as portability, adaptability, and network connectivity as well as application features such as functionality and user interface design.

ii. Characteristics of managerial decision tasks (task characteristics): aspects of the decision-making tasks that managers engage in, including 'structured-ness', mobility, interdependence, time criticality and the operational, tactical or strategic nature of the decision.

iii. Characteristics of the managers (individual characteristics): personal characteristics such as demographic attributes and computer expertise, as well as positional characteristics such as managerial level (senior, middle or operational).

Our purpose for adopting TTF is neither to test the theory, nor to measure the final TTF construct of fit itself. Rather, the three constructs from TTF described above, rather than the full set of constructs making up TTF, have been used to inform the design of the interview protocol for the study and guide the data analysis.

\section{Research Design}

Semi-structured interviews were used to collect data because this technique is well suited for exploration of the perceptions and opinions of respondents and it enables probing for more information and clarification of answers (Barriball \& While, 1994). The interview participants were recruited via the professional links of the researchers. The criteria for inclusion in the study were that the participant:

i. must be employed in a managerial role;

ii. own or have access through their employer to a tablet device;

iii. have the opportunity to use their tablet device for work purposes, if they wish.

A total of 20 participants from a business unit in a large government authority in Australia took part in the interviews. Of these, 17 used tablets to support at least some of their decisionmaking tasks at work. The summarised participants' demographic information and the tablets they use are shown in Table 1 . There was a reasonable spread of participant gender, managerial level and experience, but only a single participant from the younger 'Gen Y'. However, there was an overwhelming preference among tablet-using participants for Apple's iPad with only one using an alternative device, possibly reflecting consumer preference in the tablet market.

\begin{tabular}{|c|c|c|c|c|c|c|c|c|c|}
\hline \multicolumn{2}{|c|}{$\begin{array}{l}\text { Gender } \\
(n=20)\end{array}$} & \multicolumn{2}{|c|}{ Generation } & \multicolumn{2}{|c|}{$\begin{array}{c}\text { Managerial } \\
\text { Level }\end{array}$} & \multicolumn{2}{|l|}{$\begin{array}{l}\text { Managerial } \\
\text { Experience }\end{array}$} & \multicolumn{2}{|c|}{ Tablet } \\
\hline Male & 9 & 'Gen Y' & 1 & Senior & 4 & Less than 5 years & 6 & $\mathrm{iPad}$ & 16 \\
\hline Female 1 & 11 & ‘Gen X’ & 10 & Middle & 10 & $5-15$ years & 11 & iPad Mini & 2 \\
\hline & & 'Boomer' & 9 & Operations & 6 & Greater than 15 years & 3 & $\begin{array}{l}\text { Dell } \\
\text { Windows } \\
\text { Android }\end{array}$ & $\begin{array}{l}1 \\
1\end{array}$ \\
\hline
\end{tabular}

\section{Table 1. Participant Demographics}

An interview protocol was developed and organised into three main sections: 1 ) background of participants - to collect demographic data such as age, managerial level, managerial experience and some basic information about the participant's current tablet (if relevant); 2) tablet usage for work - to probe how managers use tablets to support their work if at all; and 3) tablet usage for decision making - to investigate how and why managers use tablets to specifically support their work-related decision-making. The latter includes the reasons why 
they use tablets, the types of decisions they make using tablets, and desired improvements (if any) to the tablet so as to better support decision-making. In the case of participants who do not use tablets for work or decision-support, they were asked why this was the case and what, if anything, would need to change for them to do so. Most of the interview questions were inspired by or adapted from the prior literature and the theoretical constructs from TTF, as discussed in Section 2.2.

In-person interviews of approximately half an hour were conducted with each participant. With the permission of the participants, all interviews were audio-recorded. All audio recordings were transcribed and loaded into NVivo, a qualitative data management and analysis software package (Neuman, 2011). A thematic coding approach was employed to analyse the data. The coding process started with the first author reading through each transcript and assigning codes according to the TTF-derived constructs as discussed in Section 2.2. New codes were also created to represent emerging themes that were found to be common among the research participants. This coding was refereed by the second and third authors. Discussions took place where the authors were able to challenge or confirm any questions or issues as they arose. These discussions during the data analysis process improved the consistency and reliability of the coding, and as a result, improved the validity of the findings presented below.

\section{Results and Discussion}

This section presents the results of the data collection and analysis, divided into three main sub-sections. The first describes the nature of how managers use tablets to support their decision-making at work. The second examines reasons why they do so, while the third describes the reasons why those who don't use their tablets for decision-support don't do so.

\subsection{Managerial Use of Tablets for Decision-Making at Work}

The participants exhibited different degrees of tablets usage to support their decision-making. One participant didn't use a tablet at work at all, while two further participants didn't use tablets for decision support. Of those who did use tablet devices for decision-support (17 participants), the majority spent less than half an hour per day on average doing so, with only three participants spending more than one hour per day using tablets to support their decisionmaking at work. While tablets were used by the participants for various tasks, on average approximately $80 \%$ of the time managers spent using tablets for work was for decisionsupport. In relation to decision-making tasks, Participant 12 said, "most of my work is dealing with these kinds of activities". To illustrate how the 17 participants who used tablets to support decision-making at work do so, we discuss four themes: usage location, tablet applications, decision activities, and decision types.

\subsubsection{Usage Location}

The locations where the participants used tablets for decision-support included meeting rooms, at home, while commuting, offices, public places such as cafes, and hotel rooms. Meeting rooms and home were the most common locations. For meetings a tablet was considered to be a more professional work device than a mobile phone and less obtrusive than a laptop. The most common activities supported by tablets in meetings were reading the agenda and looking up information. Participant 17 found the tablet "indispensable for finding information and reading." A number of participants said taking a tablet to meetings was a normal phenomenon within the organisation. Participants 13 and 17 said that everyone in meetings had a tablet. Tablets were also used at home by managers, most commonly in bed. Participant 11 noted, "(when I) wake up, I wonder what I need to do today, so I might pick it up and look at email."

Evidence suggests that tablets are mostly used when managers were away from their primary work location (only 4 participants out of 17 noted they use a tablet in their office). In addition, the decisions supported with a tablet tended to involve a high degree of mobility. Most managers mentioned when they were able to access their desktop or laptop computers at their 
primary work location, they tended to use those rather than their tablet. Network connectivity, in particular, the SIM card function, was believed to be an important aspect which assists managers to access information while away from their primary work location. As Participant 17 said, "if I go somewhere on weekends, if (clients) want me to check something, I can do it with SIM card."

\subsubsection{Tablet Applications}

Participants used various applications on their tablets to support their decision-making. A summarised list of application types is shown in Table 2, with application types grouped into higher-level categories and the number of participants who mentioned using that application type.

\begin{tabular}{lll}
\hline \multicolumn{1}{c}{ Category } & \multicolumn{1}{c}{ Application } & \multicolumn{1}{c}{$\begin{array}{c}\text { Participants } \\
\text { (n=17) }\end{array}$} \\
\hline Web-based Applications & Web Browsers & 17 \\
Communication-Driven Applications & Email Applications & 15 \\
& Video Chat Applications & 1 \\
Document-Driven Applications & Document Writers & 7 \\
& Document Readers & 7 \\
& Cloud Solutions & 2 \\
Self-Organisation Applications & Calendars & 6 \\
& Task Management Applications & 2 \\
Analytical-Support Applications & Spreadsheets & 3 \\
& Remote Access for Business & 1 \\
Other Decision-Support Applications & Intelligence & Presentation Applications \\
& Graphical Modelling Applications & 1 \\
& Social Network Applications & 1 \\
\hline
\end{tabular}

Table 2. Summary of Tablet Application Types for Decision-Making

The three most common types of tablet applications used by managers to support decision making at work were web-based, communication-driven, and document-driven applications.

Although there is a wide range of applications available on tablets, only several managers used more than five types to support decision-making. Most participants used the default applications shipped by the tablet manufacturer such as built-in web browsers, email applications, and note-taking tools. As Participant 7 said, "I don't ask for anything fancy, I am not very technical, so I don't try too much with it, just use what is there, I don't have many applications." The default applications seem to be adequate for supporting decision activities. Participant 17 said "some of the applications are already there, the most useful ones are already there, the main applications."

A closer examination of the relationship between the managerial levels and the number of tablet applications for decision support reveals that senior managers used many more tablet applications for decision-support than middle managers, who in turn used slightly more than operations managers.

A number of managers highlighted the capability of cloud-based applications to support decision-making. Managers were able to access, share, and store content through cloudenabled applications, keeping the same set of files among multiple devices. Managers used desktops, laptops, smartphones and tablets as a 'managerial technology portfolio.' Cloudbased solutions helped synchronise files within that portfolio consistently. Participant 18 said one of the important features of his tablet "is saving documents to the cloud, it is safe, I can print, that is really nice, that is a really nice feature of Pages, I can really go to parks, work, no need to bring USB keys, laptops... that is really nice." Participant 10 mentioned his tablet 
has "perfect integration with desktop environment, actually on two levels, I have my stuff integrated both with the desktop environment as well as with my mobile phone, which ensures I can access all my information at any time, and that is the most important thing."

\subsubsection{Decision Activities}

Mintzberg, Raisinghani, and Theoret (1976) define a decision as a commitment to action and the decision-making process as a set of actions and dynamic factors that begins with the identification of a stimulus for action and ends with a specific commitment to action. Using their phase-model of decision-making, the decision tasks performed by the participants on tablets were classified into four different activities: problem/opportunity identification, information gathering, solution/decision development, and solution/decision selection.

All 17 participants indicated that they used their tablet to look for more information to understand a problem or opportunity. The web browser was used in 10 out of 15 examples to support information gathering. Other applications either accompanied the web browser or were used alone such as spreadsheets, BI applications, document readers, cloud storage, and email.

Approximately two-thirds of the participants had used their tablet to identify a problem/opportunity, or to develop a solution to a problem. Of the examples that involve problem/opportunity identification, 9 out of 12 began with email or email accompanying video chat. The others began with reading meeting agendas, viewing data in a spreadsheet, and viewing a web page, respectively. In supporting the development of a solution or decision, tablet applications were split fairly evenly, with four examples mentioning email, three web browsers, two document readers, one cloud storage, and one spreadsheet.

Only around half of the participants mentioned they used their tablet to select a solution or make a final commitment to a course of action. Email was used in five examples to support the selection of a solution or choice. For instance, Participant 8 said, "in a meeting ... I would find some [information] ... in email correspondence with other staff that would possibly be a way of solving an issue that I had discovered [during the meeting], and I would use that information to make a decision."

A common pattern was found among the responses. Managers all mentioned they used a suite of applications to support the different activities/phases of decision-making. For example, Participant 1 said, "email received from (client), want to inquiry about something... I have to search for information by using Safari, the Web browser on iPad... I have to use... emails... to recall myself of how I solved the previous similar problem..."

\subsubsection{Decision Types}

To understand the types of decisions the participants were making using tablets, two classic decision typologies from Anthony (1965) and Simon (1960) were adopted. Participants were asked to estimate the percentage of decisions they made that were of each type in the two typologies. According to Anthony's (1965) strategic, tactical/managerial, operational typology, participants estimated $66 \%$ were operational decisions, $20 \%$ were tactical decisions, and $13 \%$ were strategic decisions. Of the 17 participants using tablets for decision support, 16 participants used their tablets for operational decisions, 13 for tactical, and 9 for strategic. On the other hand, using Simon's (1960) structured, semi-structured, and unstructured typology, $48 \%$ of tablet-supported decisions were structured, 33\% were semi-structured, and $18 \%$ unstructured. Of the 17 participants, all of them used their tablets for structured and semistructured decisions, while 13 used tablets for unstructured decisions. This finding contrasts with Er's (1988) characterisation of traditional PC-based DSS users. Where traditional DSS users apply the system to support less-structured and under-specified problems, tablet users tend to use applications to support more structured and clearly specified problems.

After organising the managers based on managerial level, we calculated and summarised the mean of the percentage of each decision type. Figure 1 below shows the results of this analysis. The decision types made by senior managers on their tablets split evenly from strategic to 
operational while operations managers and middle managers made more operational decisions than the other two types of decisions. Senior managers show a similarly even distribution of structured, unstructured, and semi-structured decisions, while operations managers make many more structured decisions and middle managers slightly more, than the other two types of decisions.
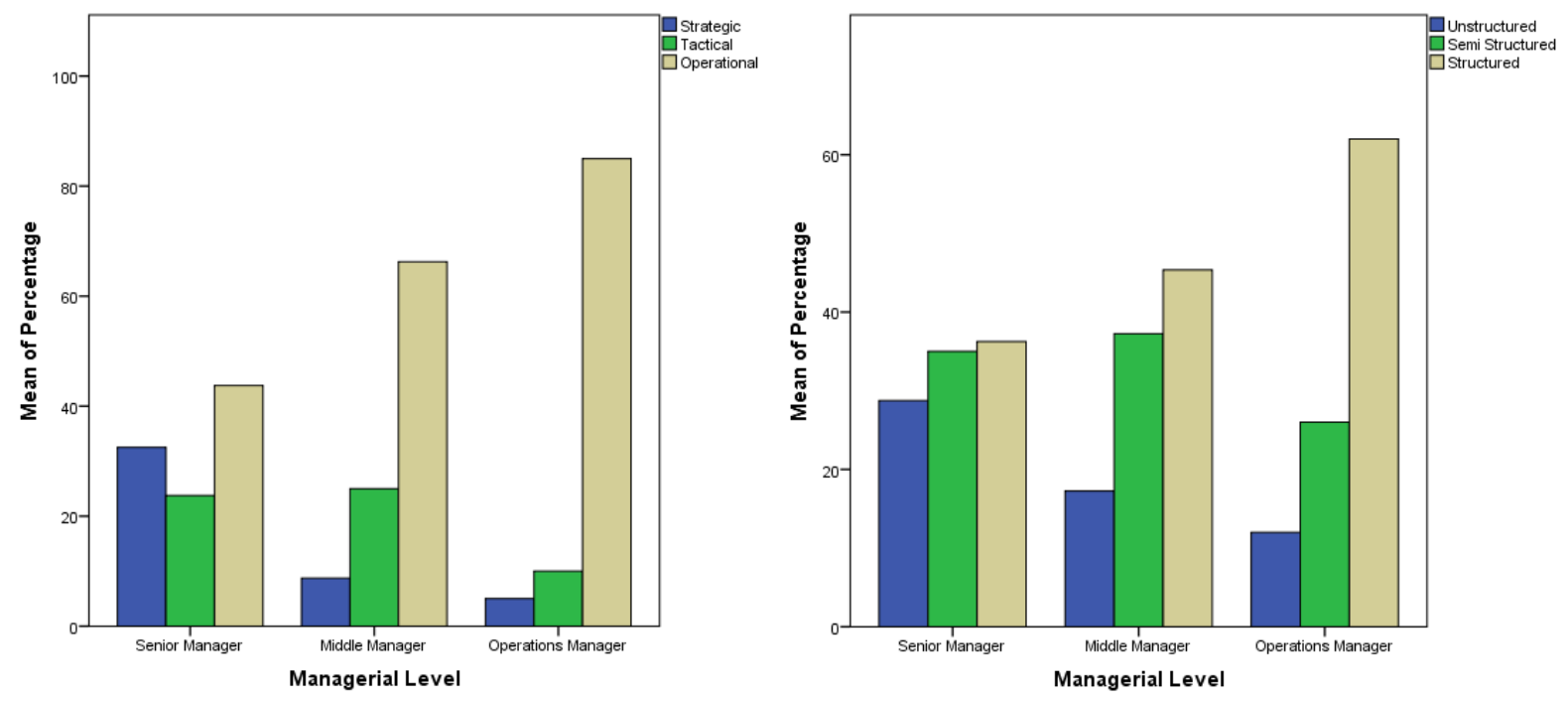

Figure 1. Mean of Percentages of Anthony's (1965) (Left) and Simon's (1960) (Right) Decision Types Sorted by Managerial Level

The figures above indicate that operations managers make more operational and structured decisions on tablets than the other two types of managers while senior managers tend to make more strategic and unstructured decisions on tablets than the other two types of managers. This is consistent with the characterisations of these types of managers by both Anthony (1965) and Simon (1960). However, in the case of all manager types, tablet-based decision-support was dominated by use for operational / structured decisions. It is unclear whether this dominance is reflective of a genuine need for support for this mix of decision tasks, or whether usage for more strategic/unstructured decision tasks is hampered by a lack of suitable tabletbased decision-support applications.

\subsection{Reasons for Using Tablets for Decision-Making}

All participants claimed that they were not required to use tablets for decision-making as part of their work routine. The most common keyword managers mentioned in relation to the reasons for using tablets for decision making were 'portability' (mentioned by 12 participants), followed by 'convenience' (6 participants), and 'ease of use' (5 participants). We have summarised and grouped these concepts into two categories: tablet characteristics and decision-task characteristics.

\subsubsection{Reasons for Use: Tablet Characteristics}

The characteristics of a technology and the consequent affordances offered to users are key drivers of its adoption. A number of tablet characteristics were identified during the study that contributed to their use for decision-support. These characteristics include portability, usability, network connectivity, and customisability.

Portability is the most evident inherited tablet characteristic from other mobile devices (Kristoffersen \& Ljungberg, 1999; Liang, Huang, Yeh, \& Lin, 2007). A number of participants explicitly and implicitly mentioned the size and weight of tablets. Compared to laptops, tablets are "smaller, lighter, more portable" (Participant 6) than a laptop and desktop. Participant 8 said, "the only reason that I use my iPad instead of my laptop is that I can take it with me." In addition, both participants (6 and 12) whose current tablets were iPad Minis, the smallest Apple tablet, cited the size of the tablet as one of the most important reasons they used it to 
support decision-making. Participant 12 said, "I like to take a small tablet to a meeting, rather than taking a big laptop... I like the size of iPad Mini, this is why I use it more." Compared to mobile phones, tablets are larger, providing more space for users to interact. Participant 17 mentioned "how I started using tablet is because I read things on iPhone initially, but the screen size was not big enough, so I bought an iPad." This is in line with the argument raised by Ozok, Benson, Chakraborty, and Norcio (2008) that tablets gained popularity by taking the mobility of laptop PCs one step further and providing a larger screen than smartphones.

McClard and Somers (2000) proposed that applications on tablets should contain features perceived as useful, and comfortable to use. The screen size should be large enough to be usable. Evidence supporting each of these features can be found in the participants' responses. Usability (ease of use and usefulness) is one of the tablet's most cited characteristics. Although a number of participants equated usability with portability, others referred to usability in terms of particular tablet applications, screen size and resolution, and the user interface. Participant 17 used their tablet for "a lot of reading" and they noted that "the design is very easy to use" in terms of reading documents. Participant 10, who uses a graphical modelling tool for decision making, said, "I draw a lot of diagrams, it is extremely simple to draw on tablet." The screen size on a smartphone is too small to effectively read a document (mentioned by Participant 17). However, in landscape orientation, a tablet screen is about as wide as a piece of paper and some participants said that it was suitable. The screen size is also better suited to writing than a smartphone's. Although there were mixed impressions of a tablet's on-screen keyboard, some managers who compared it to their smartphones were more satisfied with typing on a tablet than on a smartphone. Others mentioned the tablet's resolution, which is about the same screen resolution as a laptop's, even on a small iPad Mini. Participant 3 noted "the resolution is good, very clear". Also, the user interface was one aspect the managers found easy to use. In particular, the ability to scroll through documents displayed on the screen using the touch interface provided most managers with a good user experience, similar to the experience of physically touching a piece of paper. It also offered the ability to navigate by finger gestures such as zoom in, zoom out, and screen switching, without relying on a physical input device such as a keyboard or a mouse. Participant 14 described using their tablet as "easy to navigate."

All of the participants regarded network connectivity as an important tablet characteristic for decision support. Although only Participant 8 explicitly mentioned network connectivity as one of their reasons for using a tablet to support decision-making, the concept is present in a number of participants' answers to other questions. As discussed in Section 4.1.2, the top two categories of tablet applications used by almost all managers who use tablets to support decision making are web-based and communication-driven applications. Both of these application types require good network connectivity. Different forms of network connectivity enable users to access the Internet in different ways. Wi-Fi is the most common. Most participants explicitly mentioned that they have access to Wi-Fi in their workplace and home. A SIM card allows user to access the Internet through a mobile phone network such as the third/fourth-generation mobile network $(3 \mathrm{G} / 4 \mathrm{G})$. However, only six participants made use of the SIM function on their tablet despite all of the participants' tablets having SIM card functionality. Participant 17 said, "if I go somewhere on weekends, if (clients) want me to check something, I can do it with SIM card". Tethering to a smartphone or mobile hotspot device is another way of accessing the Internet when there is no Wi-Fi connection. Participant 14 said, "if I am somewhere where I do need connection, I use my $3 G$ smartphone. Then I can hotspot to here (the tablet)."

Although in general the participants agreed that adaptation of the tablet applications to their own needs and use situation is a desirable feature, their perceptions on the importance of such customisation capability of tablet applications is mixed. Only Participant 8 mentioned it as a reason for using the tablet for decision-making. One explanation for this could be that for the majority of participants, the use of tablets to support decision-making was voluntary. In such a context, a user is likely to have more freedom to customise the tablet and its applications than in a mandatory context. Therefore, it might be natural for them to think they can choose the 
applications they need to support their decision-making activities because the "ownership, (of the tablet) is mine" (Participant 18).

Beyond the tablet's size and lightness, its overall physical design also affects its adoption. Many agree with Participant 6, who said "it is more personal than a laptop". This theme became evident when participants talked about their work in meetings. In a meeting where a laptop was being used, other meeting attendees might feel the person was disconnected from the conversation. A tablet is also easier to carry, hold, and keep out of the way: as Participant 10 said, "I hate taking a laptop with me to meetings, it sits between you and someone else, and that is obtrusive."

\subsubsection{Reasons for Use: Decision Task Characteristics}

Apart from the characteristics of the tablet itself, the nature of the decision task also affects the use of the device to support decision-making. Participants brought up task mobility, time criticality, and complexity.

Decision task mobility was the most mentioned characteristic. Gebauer et al. (2010) define mobility as the "extent to which a mobile IS is used at different geographic locations and while the user is in motion" (p. 261). A number of participants emphasised the need to access the tablet while away from their primary work locations. Participant 10 said, "complex decisionmaking does not have a particular place or time, it's an ongoing process in your brain, and I need to be able to whip out my whole computation infrastructure at any moment at any place." Participant 20 said, "I use a tablet because it means that it is easier to get information on the spot, so it brings the information to the location which the decision is being made." Participant 13 said, "it is a good way of having a lot of document together, in one place, easy for me to carry around, mobility is the important thing, 'cause I just never know where I am going to use the data, 'cause in meetings, you would go to different locations."

In terms of time criticality and task complexity, Participant 12 said, "If I provided a quick answer or solution to something, or one that is not too difficult, that I can easily access resources and answer it, then that is the kind of thing that I would do with tablet. If something needs a bit more consideration, then I probably, would prefer to be... better a desktop, have different things open at once, things like that." Similarly, Participant 20 mentioned the immediacy of accessing information on a tablet as one of their reasons for making tabletsupported decisions, indicating that their decisions had high "immediacy." In short, the reason why some managers used a tablet for decision-making was that the decision task was relatively simple and there was a need to deal with the task quickly.

\subsection{Reasons for Not Using Tablets for Decision-Making at Work}

All participants in the study owned a tablet or had access to one through their employment, as these were criteria for inclusion in the project. However, of the 20 participants three had made the decision to cease using their tablets for work (Participants 2 and 16), or very rarely did so (less than 30 minutes per week) and never to support decision-making (Participant 15). This allowed us to explore the reasons why managers might not use a tablet for managerial decisionsupport. This adds context and further understanding to the reasons for why managers do use their tablets for decision-support.

Despite not using their tablets for decision-support at work, two of these three participants nevertheless are enthusiastic users of mobile devices. Participant 16 said "I'm all for using mobile devices" and "once you are exposed to a mobile device, you won't go back to a desktop." Participant 2 reported using their tablet at home for personal use on average an hour and a half per night for email, browsing the World Wide Web and gaming. One each of the three was from 'Gen Y', 'Gen X' and the 'Boomer' generation, and all had at least two years' experience in using tablet devices. One was an operational manager, while the other two were middle managers. Two were female, one male.

Participants 15 and 16 ultimately gave their reason for not using tablets to support decisionmaking at work as a lack of perceived value. Participant 15 said "[W]hat I know is that [the] 
technology doesn't support, doesn't give me any additional value, so that's why I never use [it]." Participant 16 said "It wasn't as good as having a piece of paper!" and "Ijust found that whole setup to be too artificial, too cumbersome, and it wasn't worth it." Participant 2 also hinted at a lack of perceived value, saying that they would use it if the organisation had purchased their tablet: "I'd feel like I was meant to be [using] it if they're paying for an iPad or whatever, but other than that I don't feel a need."

Interestingly, the reasons cited by Participants 2 and 16 for the lack of perceived value largely relate to issues of form factor, portability and usability, cited by other participants as important reasons for why they did use tablets for their work. Both participants suggested that because a tablet's size is larger than a mobile phone but smaller than a laptop, it offered neither significant portability benefits over a mobile phone, nor the usability benefits offered by a laptop computer with a larger screen and physical keyboard. Participant 2 said "I find an iPad hard to type on with a keypad...it takes me too long to do things", and Participant 16 "I could not type a document." Participant 16 found it particularly difficult and "cumbersome" to work with large documents, citing one occasion when they ended up printing a hard-copy of a large, complex document because of difficulties in searching, navigating and annotating. Participant 2 said that "when I go to meetings at work, I use my phone, which I find easier, if I'm at a meeting I feel more comfortable using this as opposed to having an iPad, because I can probably get away with, you know, they think I'm still listening, and then at [my desk] I obviously have my desktop which I find much easier to use."

Participant 16 recognised the task characteristics that lend mobile devices to supporting decision-making discussed above in Section 4.2.2: mobility, time criticality and complexity. However, they indicated that for them time critical, mobile and simple tasks were adequately supported with a mobile phone, while more complex tasks, or those less time critical or that could be performed at a desk were far better supported with a laptop computer than a tablet. Further, the difficulties in navigating and working with large documents on a tablet added to the level of complexity of the task: "For me to add another complexity with ... trying to find information..., it was just too much, too, too difficult." The nature of a tablet as a device situated between a mobile phone and a full computer meant that for both Participant 2 and 16 it had no significant value over either.

\section{Conclusion}

The results of the interviews with the 17 participants who use their tablets at work and to support their managerial decision-making highlight the importance of device portability, usability, network connectivity and customisability. However, these are also areas where poor execution of the design of the tablet hardware and software can mean that managers will abandon their usage of the devices, as described in Section 4.3. It is interesting to note that apart from information access, the tasks that these three participants referred to when discussing their reasons for not using the devices were not decision-support specific. This suggests that one possible factor in tablet use for decision-support is its value in supporting other work tasks not specifically related to decision-making. Tablet devices need to offer a clear value proposition over both laptops and smart phones for managers to use them for decision support. Ease of use, connectivity and security are essential, and if not well-executed, users will ignore pressures of task mobility and time criticality where complexity is substantially increased. Where the task is simple and not made unnecessarily complex by the use of a tablet, managers will use them for decision-support.

Of the 17 managers that we interviewed who used their tablets for work, about $80 \%$ of their work use dealt with decision activities. The most common locations where managers did so were meeting rooms and at home. Neither of these locations are their primary work locations. Web-based, communication-driven, and document-driven applications were the most common applications in supporting decision-making. All participants who used their tablets for decision support used them for information-gathering during decision-making. Managers tended to use communication driven applications to support problem/opportunity 
identification and solution/decision selection, and used web-based applications to support information gathering. Senior managers used more applications than middle and operational managers.

Structured and operational decisions were the most common types of decisions made by managers on their tablet. Also, the results further confirmed that the decision types were in line with the levels of managers, that is, on a tablet, operational managers tended to make more structured and operational decisions while senior managers made more unstructured and strategic decisions.

This research has addressed a gap in the area of tablet research, and contributes to the research field of mobile decision support. Tablets are still a relatively new type of mobile technology, and the technology has distinct characteristics from other mobile devices (Kautzner et al., 2015). This study provides a deeper understanding of the use behaviour of this mobile technology and the reasons behind it. In addition, this study focuses on managers, who are fundamentally different from other employees in organisations. The majority of prior studies on mobile decision support focus on students, general household users, operational workers, and professionals like medical practitioners (Gao, 2013). Investigating real managers offers potential value as they represent a group of users who are organisationally powerful and can influence technology adoption and use. Therefore, by focusing on tablets and managers, and investigating decision making which is an important task, this study fills two research gaps in the literature for mobile technology use.

As an exploratory study, this research has laid some of the groundwork for further investigation of tablet-based decision support and business intelligence. In particular, future research should investigate the construct of fit from TTF, looking at the alignment of mobile devices with the type of manager and decision tasks they are engaging in and how this impacts the nature of the decision support technology managers use. Of note is the fact that few managers used formal business intelligence applications on their tablets, preferring instead a more ad hoc approach, using standard communication and information management applications like email, pdf readers and the like. This may be due to a lack of fit between mobile business intelligence applications and the decision tasks of managers, or other organisational issues that inhibit access to these applications. Investigating this issue can inform mobile business intelligence vendors and application developers as to the kinds of affordances that they should focus on in developing their products. This is an area for future research.

A limitation of the study is that only 20 managers were interviewed, all from one business unit of one organisation. The results are therefore suggestive only. That being said, as an exploratory qualitative study that emphasised depth rather than breath, the number of participants exceeds that recommended by Neuman (2011). Another limitation of this study is the concentration of one specific tablet platform with 18 of the 20 participants using an iPad or iPad Mini. Only one participant used an Android device, while one used a Windows device.

\section{References}

Anthony, R. N. (1965). Planning and Control Systems: A Framework for Analysis. Cambridge, MA: Harvard University Press.

Barriball, K. L., \& While, A. E. (1994). Collecting Data Using a Semi-Structured Interview: A Discussion Paper. Journal of Advanced Nursing, 19(2), 328-335.

Buchana, Y., \& Naicker, V. (2014). The Effect of Mobile BI on Organisational Managerial Decision-Making. The Journal of Applied Business Research, 3O(4), 1003-1018.

Cil, I., Alpturk, O., \& Yazgan, H. R. (2005). A New Collaborative System Framework Based on a Multiple Perspective Approach: InteliTeam. Decision Support Systems, 39(4), 619-641.

Dishaw, M. T., \& Strong, D. M. (1999). Extending the Technology Acceptance Model with TaskTechnology Fit Constructs. Information \& Management, 36(1), 9-21. 
Er, M. C. (1988). Decision Support Systems: A Summary, Problems, and Future Trends. Decision Support Systems, 4(3), 355-363.

Gao, S. (2013). Mobile Decision Support Systems Research: A Literature Analysis. Journal of Decision Systems, 22(1), 10-27.

Gebauer, J., \& Shaw, M. J. (2004). Success Factors and Impacts of Mobile Business Applications: Results from a Mobile e-Procurement Study. International Journal of Electronic Commerce, 8(3), 19-41.

Gebauer, J., Shaw, M. J., \& Gribbins, M. L. (2010). Task-Technology Fit for Mobile Information Systems. Journal of Information Technology, 25(3), 259-272.

Goodhue, D. L. (1995). Understanding User Evaluations of Information Systems. Management Science, 41(12), 1827-1844.

Goodhue, D. L., \& Thompson, R. L. (1995). Task-Technology Fit and Individual Performance. MIS Quarterly, 19(2), 213-236.

Jarapathirun, S., \& Zahedi, F. (2007). Exploring the Influence of Perceptual Factors in the Success of Web-Based Spatial DSS. Decision Support Systems, 43(3), 933-951.

Kautzner, E., Gao, S., Yeoh, W., \& Wong, S. F. (2015). An Exploratory Study on the Factors Influencing Managers' Use of Mobile Tablets. Paper presented at the Pacific Asia Conference on Information Systems (PACIS) 2015, Singapore.

Kim, S. H. (2008). Moderating Effects of Job Relevance and Experience on Mobile Wireless Technology Acceptance: Adoption of a Smartphone by Individuals. Information \& Management, 45(6), 387-393.

Kristoffersen, S., \& Ljungberg, F. (1999). Mobile Use of IT. Paper presented at the 22nd Information Systems Reserch Seminar in Scandinavia, Keuruu, Finland.

Lee, C. C., Cheng, H. K., \& Cheng, H. H. (2007). An Empirical Study of Mobile Commerce in Insurance Industry: Task-Technology Fit and Individual Differences. Decision Support Systems, 43(1), 95-110.

Lee, P., Stewart, D., Calugar-Pop, C., Talbot, E., Mandal, S., \& Tarigoppula, A. K. (2017). Technology, Media and Telecommunications Predictions 2017. DeloitteTouche Tohmatsu Limited. Retrieved from https://www2.deloitte.com/content/dam/Deloitte/global/Documents/TechnologyMedia-Telecommunications/gx-deloitte-2017-tmt-predictions.pdf

Liang, T. P., Huang, C. W., Yeh, Y. H., \& Lin, B. (2007). Adoption of Mobile Technology in Business: A Fit-Viability Model. Industrial Management \& Data Systems, 107(8), 11541169.

Mayer, J. H., Winter, R., Stock, D., \& Scholl-Steinepreis, N. (2014). Management Support Systems on Different Devices - A Business Perspective Accommodating Managers' Growing Range of Use Situations. Paper presented at the 47th Hawaii International Conference on System Science.

McClard, A., \& Somers, P. (2000). Unleashed: Web Tablet Integration into the Home. Paper presented at the SIGCHI Conference on Human Factors in Computing Systems, New York, USA.

Mintzberg, H. (1973). The Nature of Managerial Work. Englewood Cliffs, USA: Prentice-Hall.

Mintzberg, H., Raisinghani, D., \& Theoret, A. (1976). The Structure of 'Unstructured' Decision Processes. Administrative Science Quarterly, 21(2), 246-275.

Neuman, W. L. (2011). Social Research Methods: Qualitative and Quantitative Approaches (7th ed.). Boston, USA: Pearson/Allyn and Bacon. 
O'Donnell, P., Sipsma, S., \& Watt, C. (2012). The "Hot" Issues in Business Intelligence: The View of Practitioners. Paper presented at the IFIP Working Group 8.3 International Conference on Decision Support Systems: Fusing Decision Support Systems into the Fabric of the Context, Anavissos, Greeve.

Ozok, A. A., Benson, D., Chakraborty, J., \& Norcio, A. F. (2008). A Comparative Study Between Tablet and Laptop PCs: User Satisfaction and Preferences. International Journal of Human-Computer Interaction, 24(3), 329-352.

Parkes, A. (2012). The Effect of Task-Individual-Technology Fit on User Attitude and Performance: An Experimental Investigation. Decision Support Systems, 54(2), 9971009.

Rose, D. C., Sutherland, W. J., Parker, C., Lobley, M., Winter, M., Morris, C., Twining, S., Ffoulkes, C., Amano, T., \& Dicks, L. V. (2016). Decision Support Tools for Agriculture: Towards Effective Design and Delivery. Agricultural Systems, 149, 165-174.

Sacco, A. (2015). Leading App Stores See Dramatic Increase in Business Apps. Retrieved from http://www.cio.com/article/2868067/mobile-apps/leading-app-stores-see-dramaticincrease-in-business-apps.html

Simon, H. A. (1960). The New Science of Management Decision. New York, USA: Harper.

Sneha, S., \& Varshney, U. (2009). Enabling Ubiquitous Patient Monitoring: Model, Decision Protocols, Opportunities and Challenges. Decision Support Systems, 46(3), 606-619.

Tona, O., \& Carlsson, S. A. (2014). The Impact of the Organizing Vision on Mobile BI Adoption. Paper presented at the 2014 IFIP Working Group 8.3 International Conference on Decision Support Systems: DSS 2.0, Paris.

Tona, O., \& Carlsson, S. A. (2017). Enhancing Decision-Making Efficiency Through M-BI Use. Paper presented at the 25th European Conference on Information Systems, Guimarães, Portugal. http://aisel.aisnet.org/ecis2017_rp/30/

Verkooij, K., \& Spruit, M. (2013). Mobile Business Intelligence: Key Considerations for Implementations Projects. Journal of Computer Information Systems, 54(1), 23-33.

Willis, D. A. (2011). iPad and Beyond: The Media Tablet in Business. Retrieved from https://www.gartner.com/doc/1589917/ipad-media-tablet-business

Yuan, Y., Archer, N., Connelly, C. E., \& Zheng, W. (2010). Identifying the Ideal Fit Between Mobile Work and Mobile Work Support. Information \& Management, 47(3), 125-137.

Zickuhr, K., \& Rainie, L. (2014). Tablet and E-Reader Ownership. Retrieved from http://www.pewinternet.org/2014/o1/16/tablet-and-e-reader-ownership/

Copyright: (C) 2017 Xiao, Meredith \& Gao. This is an open-access article distributed under the terms of the Creative Commons Attribution-NonCommercial 3.0 Australia License, which permits non-commercial use, distribution, and reproduction in any medium, provided the original author and AJIS are credited. 
Australasian Journal of Information Systems

2017, Vol 21, Selected papers from ACIS 2016
Xiao, Meredith \& Gao

Managers Use of Tablets in Decision Making

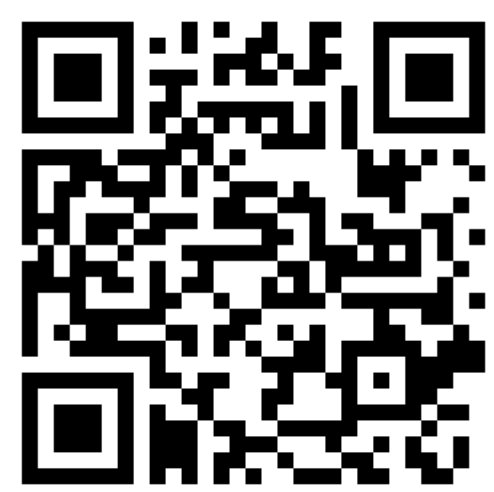

